\title{
RESISTENCIA DE LOS CULTIVARES DE PAPA MOLINERA Y AMAPOLA A Pseudomonas solanacearum*
}

\author{
SEGUNDO M. TAFUR S.*
}

\begin{abstract}
RESUMEN
La marchitez bacteriana de la papa, causada por Pseudomonas solanacearum E. F. Smith, afectó severamente al cultivar de papa Molinera en un campo ubicado en la provincia de Cajabamba, departamento de Cajamarca. Para determinar si el ataque al cultivar se debía a la pérdida de su resistencia a $P$. solanacearum o a la aparición de nuevas variantes de la bacteria, se colectaron muestras de plantas de papa con síntomas de marchitez. En el diagnóstico se determinó que de ocho cepas aisladas, siete correspondieron al (Biovar) Bv II y una al Bv I. En las pruebas de patogenicidad con estas cepas en el cultivar susceptible Revolución, se observó que la cepa del Bv I fue muy poco agresiva. Cuatro cepas aisladas recientemente (197, 199, 201 y 204) y dos antiguas (012 y 050) de la colección del Centro Internacional de la Papa, seleccionadas como las más agresivas, fueron inoculadas en plantas de papa de los cultivares Molinera, Amapola y Revolución. Amapola presentó un nivel de resistencia similar al de Molinera y su cultivo puede ser recomendado en zonas afectadas por $P$. solanacearum. Se comparó asimismo, el grado de patogenicidad de las seis cepas seleccionadas habiéndose determinado que a temperatura alta $\left(26-32^{\circ} \mathrm{C}\right)$, todas ocasionaron síntomas de marchitez, en las plantas inoculadas. A temperatura baja $\left(15-26^{\circ} \mathrm{C}\right)$ solamente dos (109 y 204) mantenían su agresividad aunque en menor grado que a temperatura alta. Dos cepas (199 y 201) incitaron un grado sumamente bajo de marchitez. La cepa 050 de comportamiento altamente agresivo a temperatura alta no ocasionó marchitez a temperatura baja. Estos resultados indican la existencia de una gran diversidad de variantes de la bacteria las mismas que pueden o no ejercer su acción patogénica en relación con la temperatura existente.
\end{abstract}

Palabras Claves Adicionales: Marchitez bacteriana de la papa, Biovar, cepas.

\section{ABSTRACT \\ Resistance of Molinera and Amapola Potato Cultivars to Pseudomonas solanacearum}

It was made a colletion of samples in Cajabamba, Department of Cajamarca, Perú to study the variability of Pseudomonas solanacearum.

\footnotetext{
* Trabajo de Tesis presentado por el autor para optar el grado de Mag. Se., Escuela Postgrado, Universidad Nacional Agraria "La Molina" Lima (Perú).

** Ingeniero Agrónomo, Programa Nacional de Papa INIPA, Estación Experimental Agropecuaria Baños del Inca, Apartado Postal 169 Cajamarca, Perú.
} 
Biovars I and II were identified, observing that Biovar I was little agresive. Six strains isolated by the International Potato Center were used to inoculate cultivars Molinera, Amapola and Revolución. The first two cultivars were more tolerant to bacterial wilt, suggesting that they can be recommended foi this character to farmers. The reaction of cultivars to the six strains depended much on temperature conditions. At 26$32^{\circ} \mathrm{C}$ all cultivars were susceptible, while at $15-26^{\circ} \mathrm{C}$ only two strains were aggressive and in a lesser degree, It was concluded that probably many biotypes exist which interact with temperature to produce a variable degree on potato infections.

Additional Index Words: bacterial wilt, strains, biotypes.

El uso de cultivares resistentes a la marchitez bacteriana de la papa, es una alternativa promisoria para contrarrestar los efectos de esta enfermedad.

Por muchos años, los fitomejoradores han buscado variedades resistentes y han tenido éxito en maní y tabaco pero en papa los logros obtenidos han sido lentos, pues las variedades que se desarrollan con altos niveles de resistencia en un lugar dado, pueden no sobrevivir en otras áreas geográficas debido a la presencia de variantes específicas del patógeno, o a que la resistencia no se manifiesta bajo ciertas condiciones ambientales (1).

El cultivar Molinera de probada resistencia a variantes de la raza 3 en la sierra del Perú, Kelman (8) fue ligeramente susceptible, Hayward (5) en San Ramón a 900 metros de altitud; sin embargo a comienzos de 1982 fueron detectados en Cajabamba (Dpto. de Cajamarca) a 2655 m de altura, cultivos de papa del cultivar Molinera fuertemente afectados por $P$. solanacearum. Lo anterior hizo pensar que la resistencia de este cultivar estaría siendo afectada por la aparición de nuevas variantes de la bacteria, y sembró la duda sobre la promoción de su cultivo o el uso de Solanum phureja como fuente de resistencia de la cual provino la var. Molinera. Paralelamente a esta observación, se encontró que en Cutervo (Dpto. de Cajamarca) se viene cultivando con éxito un cultivar de papa conocido por los agricultores como "Amapola" por tener abundantes flores de color blanco, la misma que surgió del grupo del cual fueron seleccionados los cultivos Caxamarca y Molinera, e hizo presumir que tenía resistencia a $P$. solanacearum.

Los objetivos de este trabajo fueron determinar la respuesta de los cultivares de papa Molinera y Amapola, a la inoculación con cepas de $P$. solanacearum procedentes del departamento de Cajamarca y Huánuco; como testigo se utilizó el cultivar susceptible Revolución. Además, comparar la patogenicidad de cepas antiguas obtenidas en 1973 y 1976 y nuevas aisladas en 1982, estas últimas aisladas de cultivares susceptibles y de otros desarrollados para resistencia a la marchitez bacteriana. Finalmente, determinar si estos cultivares tienen resistencia duradera o si se han desarrollado nuevas variantes del patógeno. 


\section{MATERIALES Y MÉTODOS}

El presente trabajo se realizó en los laboratorios e invernaderos del Centro Internacional de la Papa (CIP) distrito La Molina, LimaPerú, durante 1982-84. Para la prospección de la bacteria $P$. solanacearum se colectaron muestras de plantas con síntomas de marchitez, en campos ubicados en las provincias de Cajabamba, Chota y Cutervo (Dpto. de Cajamarca) donde la incidencia de esta enfermedad fue severa en años pasados. Para el aislamiento de la bacteria en cultivo puro, se hicieron estriados sucesivos en medio Kelman sin tetrazolio. Para el reconocimiento de la morfología y color de las colonias se hicieron estriados en medio Kelman en el que las colonias del tipo silvestre se diferenciaban de las colonias mutantes avirulentas porque las primeras eran de aspecto fluido, grandes y tenían poca o ninguna pigmentación (formazán), mientras que las mutantes avirulentas eran mantecosas, pequeñas y altamente pigmentadas Kelman (9).

Para la determinación de biovares (Bvs) se usó el método de Hayward modificado por French $(3,4)$ el cual establece cuatro Bvs, y se basa en la utilización de disacáridos (lactosa y maltosa) y la oxidación de hexoalcoholes (manitol y sorbitol).

La agresividad de las cepas fue probada en el cultivar de papa Revolución (Solanum tuberosum sbsp andigena), mediante la inoculación de las plantas con suspensiones de $5 \times 10^{7}$ y $10^{8} \mathrm{ufc} / \mathrm{cm}^{3}$. La inoculación de las plantas se hizo aplicando al suelo $45 \mathrm{~cm}^{3}$ de la suspensión bacteriana preparada en la concentración deseada, la cual previamente fue uniformizada a densidad óptica 0.1 en un espectrofotómetro Baush \& Lomb Spectronic 20 (600 nm) que equivale aproximadamente $10^{8} \mathrm{ufc} / \mathrm{cm}^{3}$.

Los síntomas se evaluaron con una escala de cinco grados en la que: 1 = plantas sin síntomas; 2 =un folíolo o una hoja marchita; 3 = un tercio de la planta marchita; 4 = dos tercios de la planta marchita y 5 = toda la planta marchita.

La agresividad de las cepas fue probada en el cultivar de papa se determinó inoculando seis cepas seleccionadas como las más agresivas, las mismas que fueron aisladas de variedades susceptibles y de aquellas seleccionadas como resistentes a $P$. solanacearum.

\section{RESULTADOS}

De las muestras se seleccionaron ocho cepas de zonas ecológicas representativas y distintos cultivares de papa. En las pruebas de biovares se determinó que siete correspondían a Bv II y uno al Bv I. Este último fue aislado simultáneamente con una cepa del Bv II de una misma planta del cultivar Amapola (Tabla 1) 
TABLA 1. Biovares de P. solanacearum determinados para las cepas procedentes del departamento de Cajamarca aisladas de diferentes cultivares de papa.

\begin{tabular}{lcccc}
\hline $\begin{array}{l}\text { Cepa } \\
\text { No. }\end{array}$ & Biovar & Cultivar de origen & $\begin{array}{c}\text { Procedencia } \\
\text { (Distrito) }\end{array}$ & Altitud \\
\hline 197 & II & Molinera & Cajamarca & 2630 \\
198 & II & Molinera & Cauday & 2950 \\
200 & II & Mariva & Chota & 2400 \\
201 & II & Ranrahirca & Cutervo & 2350 \\
$202 *$ & II & Amapola & Huambos & 2450 \\
$203^{*}$ & I & Amapola & Huambos & 2450 \\
204 & II & Molinera & Huambos & 2450 \\
\hline
\end{tabular}

* Cepas aisladas de una misma planta.

En las pruebas de patogenicidad realizadas con 15 cepas de P. solanacearum en las que estaban incluidas cepas antiguas y nuevas, se observó que la cepa 203 ( $\mathrm{Bv}$ I) mostró una baja capacidad patogénica inoculada con $10^{8} \mathrm{ufc} / \mathrm{ml}$ y no ocasionó síntomas a menor nivel de inoculo. Como resultado de estas pruebas, se seleccionaron seis cepas consideradas como las más agresivas y representativas. Para la selección de cepas se tuvo en cuenta el año de aislamiento y se nominaron antigua (A) a las aisladas en 1973-1976 y nuevas (N) a las aisladas en 1982; además se consideró al cultivar de papa del cual provinieron ya sea susceptibles (S) o con genes de resistencia (R), se formó así tres grupos de cepas: AS (012 y 050) NS (199 y 201) y NR (197 y 204).

En la respuesta de las variedades de papa Molinera y Amapola a la inoculación con las seis cepas de $P$. solanacearum se determinó que a temperatura alta $\left(26-32^{\circ} \mathrm{C}\right)$ y baja $\left(15-26^{\circ} \mathrm{C}\right)$ y concentraciones de inoculo de $10^{7}$ y $10^{8} \mathrm{ufc} / \mathrm{ml}$, ambas variedades presentaron un nivel de resistencia estadísticamente similar con diferencias significativas a la variedad Revolución usada como testigo susceptible.

En la comparación de la patogenicidad de cada una de las seis cepas bacterianas, se observó que a temperatura alta $\left(26-32^{\circ} \mathrm{C}\right)$ y al $10^{7} \mathrm{ufc} / \mathrm{ml}$, la cepa 050 se comportó como la más agresiva, las cepas 012, 197, 201 y 204 ocasionaron marchitez en un grado similar y la 199 fue la menos agresiva; al incrementar el nivel de inoculo a $10^{8} \mathrm{c} / \mathrm{ml}$ y las cepas 050, 197, 201 y 204 tuvieron igual comportamiento y definieron significativamente con las cepas $012 \mathrm{y}$ 199, las mismas que entre sí también fueron diferentes; sin embargo, cuando las plantas inoculadas se pusieron a temperatura baja (15$26^{\circ} \mathrm{C}$ ), con un nivel de inoculo de $10^{7} \mathrm{ufc} / \mathrm{ml}$ solamente las cepas 197, 199 y 204 ocasionaron síntomas de marchitez, incrementándose estos al inocularse con $10^{8} \mathrm{ufc} / \mathrm{ml}$, donde la cepa 201 también ocasionó marchitez pero fue en una incidencia muy baja al igual que la 199. 


\section{DISCUSIÓN Y CONCLUSIONES}

Durante una década fue considerado al biovar (Bv) II como el único causante de marchitez bacteriana en la sierra del departamento de Cajamarca en altitudes comprendidas entre 2350 y 2950 m.s.n.m., no obstante, el encuentro del Bv I (cepa 203) en una misma planta en la que hubo también el Bv II a 2450 m.s.n.m., podría indicar que este $\mathrm{Bv}$ también esté presente en forma endémica en esta zona, sin ocasionar síntomas aparentes de marchitez o podría ser que fue introducido en forma de infección latente conjuntamente con el Bv II, procedente de zonas lejanas de menor altitud. De 130 cepas de $P$. solanacearum, aisladas entre 1973 y 1982, solamente una (Cepa 203) fue del Bv I y el resto fueron del Bv II.

Los resultados de la inoculación de seis cepas de $P$. solanacearum a plantas de papa de los cultivares Molinera, Amapola y Revolución en las que Molinera y Amapola se marchitaron en un mismo grado encontrándose diferencias significativas con Revolución usada como testigo susceptible, indicando que Molinera aún mantiene su nivel de resistencia atribuida inicialmente y Amapola al tener igual nivel de resistencia, su cultivo sería también recomendado en zonas afectadas por marchitez bacteriana. Estos niveles de resistencia que no se trata de inmunidad, son útiles en la agricultura, puesto que la papa se cultiva a temperaturas más bajas que las usadas en estos experimentos que son más propicias para el desarrollo de la marchitez.

La variación en el comportamiento de las seis cepas en estudio, nos indica la existencia en la naturaleza de una gran diversidad de variantes del Bv II de $P$. solanacearum, cuyos comportamientos varían de acuerdo con la temperatura existente; así, la cepa 050 de comportamiento muy agresivo a temperatura alta, no ocasionó marchitez a temperatura baja, donde las cepas del grupo NR ejercieron su capacidad patogénica en mayor grado que la NS.

La capacidad de las cepas NR (197 y 204) de producir marchitez cuando las NS (199 y 201) producen poco y las AS (012 y 050) nada, puede deberse a una mayor agresividad que les permite ser patógenas aún en condiciones frías adversas, aunque también podría deberse a su adaptación al frío lo cual ha sido reconocido en varias oportunidades Ciampi (2). Esto resalta el serio peligro que puede significar cuando se siembra semilla aparentemente sana con infección latente procedente de zonas altas, en lugares de menor altitud.

\section{REFERENCIAS BIBLIOGRÁFICAS}

1. Centro Internacional de la Papa. 1980. Enfoque provisional de control de la marchitez bacteriana de la papa, (circular CIP 8).

2. Ciampi, L.; Sequeira L. 1980. Influence of temperature virulence of race 3 strains of Pseudomonas solanacearum. Amer, Potato J. 57: 307-317.

3. French, E. R. 1978. Culture media for Pseudomonas 
solanacearum isolation, identifications and maintainance. In: Proc. II Reg. Symp. Potato Production S. E. Asia and the pacific: Pathogens and pests of potatoes in the Tropics. Los Baños, Laguna, Philipines. p. 131-137.

4. French, E. R. 1979. Classification, distribution and origin Pseudomonas solanacearum. In: Developments in control potato bacterial disease. CIP. Lima, Perú p. 28-35.

5. Hayward, A. C. 1964. Characteristics of Pseudomonas solanacearum. J. Appl. Bact 27: 265-277.

6. Hayward, A. C. 1976. Some techniques of importance in the identification of P. solanacearum. In: Planning, conference and workshop on the ecology and control of bacterial wilt caused by Pseudomonas solanacearum. N. Carolina Sta. Univ., Raleigh, p. 137-142.

7. Herrera, I. A., French, E. R. 1970, Strains de Pseudomonas solanacearum aislados de papa en Perú. Investigaciones Agropecuarias del Perú (Ministerio de Agricultura) 1: 47-52.

8. Kelman, A. 1953. The bacterial wilt caused by $P$. solanacearum. N. Carol Agr. Exp. Sta. (Technical Bulletin).

9. Kelman A. 1954. The relationship of patogenicity in Pseudomonas solanacearum to colony appearance on a tetrazolium medium. Phytopathology 44: 693-695. 